\title{
Thermodynamic and Polarization Parameters of Dibenzo-18- crown- 6 in Mixed Methanol Water Solvents
}

\author{
Esam A. Gomaa \\ Chemistry Department, Faculty of Science, Mansoura University, Mansoura, 35516, Egypt
}

\begin{abstract}
The different thermodynamic parameters for the solvation (Free energies, enthalpies, and entropies) $\left(\Delta \mathrm{G}_{\mathbf{s}}, \Delta \mathrm{H}_{\mathbf{s}}\right.$ $\& \mathrm{~T} \Delta \mathrm{S}_{\mathbf{s}}$ ) for dibenzo-18-crown-6 in mixed methanol-water solvents were calculated form the experimental solubility data at different temperatures. From the experimental refractive indices and densities for the saturated solutions, the total polarization $\left(\mathrm{P}_{\mathbf{t}}\right)$, polarizability $(\alpha)$, induced dipole moment $(\mu)$ and the contribution of the electronic permittivity $\left(\varepsilon_{\infty}\right)$ were evaluated. The solvation behavior of the crown ether used in these media was discussed in view of the estimated refraction and polarization parameters.Since dibenzo 18-crown-6 has a wide applications in analytical, industrial and biological ones, then the aim of this study is to explain its solvation behaviours in methanol.
\end{abstract}

Keywords Crown Ether, Solvation, Thermodynamic Parameters, Polarization, Mixed Methanol Water Solvents

\section{Intoduction}

In recent years, macrocyclic ligands have been used in ion chromatography as components of both the stationary and mobile phases. The interest in these molecules derives from their selectivity in binding specificcations. Some labs focused on the use of macro-cycles in ion chromatography in the separation of both cations and anions .Nakagawa et al. investigated the use of crown ethers in the mobile phase for the separation of amine cations, peptides, and sulfonic acids. They showed that the increase in capacity factors is related to the stability of the complex for those compounds that form complexes with the crown ether. They also showed that the concentration of crown ether influences the capacity factors for some compounds. Peak resolution between mono- and divalent cations using an unmodified silica gel column. The improved resolution is due to adsorption of 18 -crown- 6 onto the stationary phase and the formation ofmacrocycle-cation complexes with selected metal ions . The $\log K$ values indicate those metal ions that bind 18-crown-6 preferentially .Recently, Dionex developed the Ion Pac CS15 analyticalcolumn, which like its precursor the CS12A,contains phosphonate and carboxylate functionalgroups, but in addition contains 18-crown-6 groups[1-5].

Macrocyclic polyethers (crown ethers) are a family of compounds which possess the ability to transport ionic species across natural and artificial membranes. Because of this characteristic, they have wide applications in industry and

* Corresponding author:

esam_1947@hotmail.com (Esam A. Gomaa)

Published online at http://journal.sapub.org/ajps

Copyright (C) 2012 Scientific \& Academic Publishing. All Rights Reserved are being investigated for their potential as pharmacologic agents.However, these compounds are highly cytotoxic in both prokaryotes and eukaryotes. Because of the cytotoxicity of crown ethers, an investigation of the potential genotoxicity of these compounds in Salmonella typhimurium was used[6].

Crown ethers are very important, especially in application in thermodynamic studies[7], solvent extraction of divalent and monovalent ions[8], selective synergistic solvent extraction[9] and competitive complexation of some alkaline earths and transition metal ions[10]. Synthesis, characterization, crystal structure if some salts with dibenzo-18-crown- 6 and dibenzo-24-crown-8 macromolecules[11] are valuable ones. Therefore, studying the physical properties of the crown ethers, especially dibenzo-18-crown-6 are wanted to follow their behaviour in solutions like, apparent molar volumes and adiabatic compressibility[12].

The aim of this work is to evaluate the solvation, thermodynamic and polarization parameters of dibenzo-18crown-6 in mixed methanol-water solvents at different temperatures.

\section{Experimental}

Dibenzo-18-crown-6 (DB18C6) was supplied from Merck. Methanol of BDH was used. Saturated solutions of DB18C6 were prepared by shaking $10 \mathrm{ml}$ of different percentages of methanol and water in $15 \mathrm{ml}$ glass tubes containing excess of the solid substance in a thermostatic water bath of the type Assistant 3193 at time intervals for a period of $2-3$ weeks at $25,30,35$ and $40^{\circ} \mathrm{C}$. The molal solubility's of DB18C6 were measured (gravimetrically) by drying $1 \mathrm{ml}$ of 
the saturated solutions in small aluminium dishes or small beakers under a tungsten lamp to avoid scattering of the solutions as explained by Gomaa[13,14] .

The molal solubilities of DB18C6 in mixed $\mathrm{MeOH}-\mathrm{H}_{2} \mathrm{O}$ solvents were also confirmed by spectrophotometric measurements using (Unicom UV2-100 UV/ visible spectrometer V 3.32 ) by dissolving the above residues after evaporation in pure methanol and measuring the absorption at wave length ( $\lambda$ ) of $275 \mathrm{~nm}$ done using different concentrations of DB18C6 in methanol mixture at the same wave length, small differences were observed in both measurements, there for the mean values were listed in Table 1 .

The solubilities were read by the use from the standard curve. The refractive indices of the saturated solutions of $\mathrm{DB} 18 \mathrm{C} 6$ were measured at $25,30,35$ and $40^{\circ} \mathrm{C}$ using a refractometer ATAGO 3T No.52507, $1 \mathrm{ml}$ weighing bottle was used for measuring the densities of the saturated DB18C6 in mixed $\mathrm{MeOH}-\mathrm{H}_{2} \mathrm{O}$ solvents at different temperatures which used for calculating the molar volume by dividing the molecular weight by density values. The heat of evaporation for solid DB18C6 was done by using DSC (Differential Scanning Calorimeter) apparatus of the type Mettler TA 3000, DSC25, made in Swizzerland.

\section{Results and Discussion}

The molal solubilities of DB18C6 were determined as reported in the experimental part at $25,30,35$ and $40^{\circ} \mathrm{C}$ in $\mathrm{MeOH}-\mathrm{H}_{2} \mathrm{O}$ mixtures with energy of $\pm 0.001 \mathrm{~g} / \mathrm{L}$. Their solubility are shown in Table(1) which recorded from the average of minimum experiments with experimental error of $\pm 0.01$

The solvation free energies for neutral compounds like tetraphenyl methane $\left(\mathrm{Ph}_{4} \mathrm{C}\right)$, tetra phenyl germanium $\left(\mathrm{Ph}_{4} \mathrm{Ge}\right)[8,9] \mathrm{DB} 18 \mathrm{C} 6$ in mixed $\mathrm{MeOH}-\mathrm{H}_{2} \mathrm{O}$ solvents were calculated from the molal solubility[10] by using the following equation (1):

$$
\Delta \mathrm{G}_{\mathbf{s}}=-2.303 \mathrm{RT} \log \mathrm{C}
$$

Where $\mathrm{C}$ is the molal solubility of the crown ether used.

The transfer free energies for DB18C6 from water to mixed $\mathrm{MeOH}-\mathrm{H}_{2} \mathrm{O}$ solvents were calculated by applying equation (2) without correcting the activity coefficient[15].

$$
\Delta \mathrm{G}_{\mathbf{t}}=-2.303\left(\log \mathrm{C}_{\text {solvent }}-\log \mathrm{C}_{\mathrm{H} 2 \mathrm{O}}\right)
$$

Table 1. The solubility products of dibenzo -18 -crown 6 (DB18C6) in mixed methanol - water mixtures at different temperatures

\begin{tabular}{ccccc}
\hline Vol \% of $\mathrm{MeOH}$ & $25^{\circ} \mathrm{C}$ & $30^{\circ} \mathrm{C}$ & $35^{\circ} \mathrm{C}$ & $40^{\circ} \mathrm{C}$ \\
\hline 0.000 & 0.0167 & 0.0205 & 0.0236 & 0.0302 \\
0.047 & 0.0206 & 0.0239 & 0.0292 & 0.0367 \\
0.10 & 0.0239 & 0.0268 & 0.0318 & 0.0395 \\
0.151 & 0.0275 & 0.0315 & 0.0342 & 0.0419 \\
0.228 & 0.0303 & 0.0345 & 0.0366 & 0.0429 \\
0.323 & 0.0325 & 0.0389 & 0.0408 & 0.0483 \\
0.400 & 0.0352 & 0.0439 & 0.0467 & 0.0558 \\
0.509 & 0.0397 & 0.0470 & 0.0489 & 0.0580 \\
0.640 & 0.0459 & 0.0509 & 0.0529 & 0.0609 \\
0.800 & 0.0518 & 0.0550 & 0.0584 & 0.0651 \\
1.000 & 0.0562 & 0.0594 & 0.0652 & 0.0759 \\
\hline
\end{tabular}

From the relation of $(-\log C)$ versus $1 / T$, the enthalpy of solvation $\left(\Delta \mathrm{H}_{\mathbf{s}}\right)$ are calculated where the slope equals $\Delta \mathrm{H}_{\mathbf{s}}$ $/ 2.303 \mathrm{R}$. From the values of $\Delta \mathrm{G}_{\mathrm{s}}$.

$$
\Delta \mathrm{G}_{\mathbf{t}}=\Delta \mathrm{G}_{\mathbf{s}}-\Delta \mathrm{G}_{\mathbf{w}}
$$

Where $\Delta \mathrm{G}_{\mathbf{s}}$ and $\Delta \mathrm{G}_{\mathbf{w}}$ are the solvation free energies in mixed solvent and water as reference solvent and $\Delta \mathrm{H}_{\mathrm{s}}$ the values of $\mathrm{T} \Delta \mathrm{S}_{\mathrm{s}}$ of solvation at $25^{\circ} \mathrm{C}$ can be calculated using Gibbs equation (4):

$$
\Delta \mathrm{G}_{\mathrm{s}}=\Delta \mathrm{H}_{\mathrm{s}}-\mathrm{T} \Delta \mathrm{S}_{\mathrm{s}}
$$

The calculated values of the different thermodynamic salvation parameters $\left(\Delta \mathrm{G}_{\mathbf{s}}, \Delta \mathrm{H}_{\mathbf{s}}\right.$ and $\left.\mathrm{T} \Delta \mathrm{S}_{\mathbf{s}}\right)$ for DB18C6 in mixed $\mathrm{MeOH}-\mathrm{H}_{2} \mathrm{O}$ solvents at $25^{\circ} \mathrm{C}$ were tabulated in Table (2) together with their transfer values $\Delta \mathrm{G}_{\mathbf{t}}, \Delta \mathrm{H}_{\mathbf{t}} \& \mathrm{~T} \Delta \mathrm{S}_{\mathbf{t}}$ from mixed solvent to water as standard solvent[16].

Table 2. The solvation free energies $\left(\Delta \mathrm{G}_{\mathrm{s}}\right)$, enthalpy of solvation $\left(\Delta \mathrm{H}_{\mathrm{s}}\right)$, entropy of solvation $\left(\mathrm{T} \Delta \mathrm{S}_{\mathrm{s}}\right)$ and their transfer values $\Delta \mathrm{G}_{\mathrm{t}} \& \Delta \mathrm{H}_{\mathrm{t}} \& \mathrm{~T} \Delta \mathrm{S}_{\mathrm{t}}$ for DB18C6 in mixed $\mathrm{MeOH}-\mathrm{H}_{2} \mathrm{O}$ solvents $25^{\circ} \mathrm{C}$ (in $\mathrm{KJ} /$ mole)

\begin{tabular}{ccccccc}
\hline $\begin{array}{c}\text { Vol \% } \\
\text { of } \\
\mathrm{MeOH}\end{array}$ & $\Delta \mathrm{G}_{\mathbf{s}}$ & $\Delta \mathrm{G}_{\mathbf{t}}$ & $\Delta \mathrm{H}_{\mathbf{s}}$ & $\Delta \mathrm{H}_{\mathbf{t}}$ & $\mathrm{T} \Delta \mathrm{Ss}$ & $\mathrm{T} \Delta \mathrm{S}_{\mathbf{t}}$ \\
\hline 0 & 10.129 & 0 & 31.112 & 0 & 41.241 & 0 \\
10 & 9.609 & 0.520 & 29.870 & -1.242 & 34.479 & -1.762 \\
20 & 9.242 & 0.887 & 24.891 & -6.221 & 34.133 & -7.108 \\
30 & 8.894 & 1.235 & 23.894 & -7.218 & 32.788 & -8.453 \\
40 & 8.654 & 1.475 & 22.540 & -8.572 & 31.194 & -10.047 \\
50 & 8.481 & 1.648 & 21.500 & 9.612 & 29.981 & -11.260 \\
60 & 8.283 & 1.846 & 21.810 & -9.302 & 30.093 & -11.148 \\
70 & 7.985 & 2.144 & 21.182 & -9.930 & 29.169 & -12.072 \\
80 & 7.626 & 2.503 & 21.026 & -10.086 & 28.652 & -12.589 \\
90 & 7.327 & 2.802 & 19.026 & -12.086 & 26.353 & -14.888 \\
100 & 7.125 & 3.004 & 14.852 & -16.260 & 21.477 & -19.264 \\
\hline
\end{tabular}

It was observed from Table (2) that by more increasing the percentage of $\mathrm{MeOH}$ in the mixed solvents the transfer free energies, enthalpies and entropies of solvation of DB18C6 increase in their negative values favouring more solvation behaviour.

The measured refractive indices for the saturated DB18C6 solutions in $\mathrm{MeOH}-\mathrm{H}_{2} \mathrm{O}$ solvents are shown in Table (3). The plot of refractive index versus absolute temperature follows a linear law

$$
\mathrm{n}_{\mathrm{d}}=\mathrm{C}+\mathrm{DT}
$$

\begin{tabular}{|c|c|c|c|c|c|c|}
\hline \multirow{2}{*}{$\begin{array}{l}\text { Vol\% of } \\
\mathrm{MeOH}\end{array}$} & \multicolumn{4}{|c|}{$\mathrm{n}_{\mathbf{d}}$} & \multirow{2}{*}{$\mathrm{C}$} & \multirow{2}{*}{ Dx $10^{4}$} \\
\hline & $25^{\circ} \mathrm{C}$ & $30^{\circ} \mathrm{C}$ & $35^{\circ} \mathrm{C}$ & $40^{\circ} \mathrm{C}$ & & \\
\hline 0 & 1.3332 & 1.3326 & 1.3319 & 1.3312 & 1.3337 & -5 \\
\hline 20 & 1.3368 & 1.3364 & 1.3355 & 1.3348 & 1.3374 & -5.4 \\
\hline 40 & 1.3408 & 1.3398 & 1.3388 & 1.3376 & 1.3417 & -6.4 \\
\hline 60 & 1.3420 & 1.3404 & 1.3388 & 1.3368 & 1.3434 & -6.8 \\
\hline 80 & 1.3390 & 1.3372 & 1.3365 & 1.3227 & 1.3402 & -7.8 \\
\hline 100 & 1.3304 & 1.3276 & 1.3255 & 1.3222 & 1.3313 & -8.8 \\
\hline
\end{tabular}

Table 3. Refractive indices $\left(\mathrm{n}_{\mathbf{d}}\right)$ for $\mathrm{DB} 18 \mathrm{C} 6$ in mixed $\mathrm{MeOH}-\mathrm{H}_{2} \mathrm{O}$ solvents at different temperatures and C, D factors for equation (5)

By means of least-squares method it was found C and D values are given in Table 3 also with error of $C$ and $D \pm 0.003$ and error for $n_{d}$ is $\pm 0.02 \%$. The observed $D$ values increase in their values whereas $C$ values are almost constant indicating more solvent effect by increasing percentage of $\mathrm{MeOH}$. 
From Clausius - Mosotti and Maxwell derivation[17] a relationship connecting the dielectric constant of a substance with its refractive index for low frequency radiation namely $\mathrm{n}^{2}{ }_{\mathbf{d}}$ as in case of DB18C6, so that, the molar refraction (R) equal the molar polarization $(\mathrm{P})$ which may be equated by:

$$
\begin{gathered}
P=R=\frac{n^{2}-1}{n^{2}+2} V m \\
V m=\frac{\varepsilon^{2}-1}{\varepsilon^{2}+2}=\frac{4 \pi N \alpha}{3}
\end{gathered}
$$

Where R, molar refraction, $\mathrm{P}$ molar polarization, $\mathrm{n}\left(\mathrm{n}_{\mathrm{d}}\right)$ refractive index, $\varepsilon$, dielectric constant, $\mathrm{V}_{\mathrm{m}}$ molar volume $(\mathrm{M} / \mathrm{d}), \alpha$ the polarizability and $\mathrm{N}$ is Avogadro's number. The molar volumes $\mathrm{V}_{\mathrm{m}}, \mathrm{P}$ and $\alpha$ for saturated solutions of DB18C6 in mixed $\mathrm{MeOH}-\mathrm{H}_{2} \mathrm{O}$ solvents are presented in Table (4) at different temperatures. This results indicates the increase in their values with more increasing $\mathrm{MeOH}$ content in the mixtures favouring more solvaton behavior.

The molar refraction for DB18C6 was calculated in its solid state from the summation of bond refraction[18] and was found to be 57.626. Also the standard polarizability for solid DB18C6 was calculated by adding the bond polarizabilities and found to be $2.12 \times 10^{-23} \mathrm{C}$.C/mole. In comparing these values with values in Table (4), it was found that increase in molar polarization and polarizabilies for DB18C6 on mixed $\mathrm{MeOH}-\mathrm{H}_{2} \mathrm{O}$ solvents.

On drawing the relation between $\mathrm{P}$ versus $1 / \mathrm{T}$ straight lines were obtained (Fig.1) with slope $\mathrm{B}$ and intercept equal to the sum of atomic polarization $\left(\mathrm{P}_{\mathbf{A}}\right)$ and electronic polarization $\left(\mathrm{P}_{\mathbf{E}}\right)$ [17]. The dipole moment can be calculated by using equation 8 :

$$
\mu=0.0181 \sqrt{B}
$$

\begin{tabular}{|c|c|c|c|c|c|c|c|c|}
\hline \multirow[t]{2}{*}{ Vol\%of $\mathrm{MeOH}$} & \multicolumn{3}{|c|}{$\mathrm{V}_{\mathrm{m}}\left(\mathrm{cm}^{3} / \mathrm{mole}\right)$} & \multicolumn{5}{|c|}{$\mathrm{P}$ (c.c / mole) } \\
\hline & $25^{\circ} \mathrm{C}$ & $30^{\circ} \mathrm{C}$ & $35^{\circ} \mathrm{C}$ & $40^{\circ} \mathrm{C}$ & $25^{\circ} \mathrm{C}$ & $30^{\circ} \mathrm{C}$ & $35^{\circ} \mathrm{C}$ & $40^{\circ} \mathrm{C}$ \\
\hline 0 & 354.73 & 355.43 & 356.49 & 364.14 & 73.006 & 73.150 & 73.108 & 74.554 \\
\hline 20 & 364.050 & 367.69 & 368.93 & 370.62 & 74.737 & 74.411 & 75.461 & 76.112 \\
\hline 40 & 376.84 & 380.52 & 382.60 & 385.10 & 79.158 & 79.723 & 79.941 & 80.204 \\
\hline 60 & 389.13 & 396.62 & 403.77 & 408.23 & 82.000 & 83.224 & 84.364 & 85.047 \\
\hline 80 & 404.05 & 411.28 & 418.11 & 428.51 & 85.566 & 85.566 & 86.823 & 85.651 \\
\hline \multirow[t]{9}{*}{100} & 451.24 & 454.37 & 457.08 & 460.21 & 92.159 & 92.084 & 92.092 & 91.866 \\
\hline & \multirow[t]{2}{*}{ Vol\%of $\mathrm{MeOH}$} & \multicolumn{6}{|c|}{$\alpha\left(\mathrm{X} 10^{23}\right.$ c.c $/$ mole $)$} & \\
\hline & & & $25^{\circ} \mathrm{C}$ & $30^{\circ} \mathrm{C}$ & $35^{\circ} \mathrm{C}$ & & $40^{\circ} \mathrm{C}$ & \\
\hline & 0 & & 2.894 & 2.899 & 2.898 & & 2.954 & \\
\hline & 20 & & 2.962 & 2.949 & 2.991 & & 3.017 & \\
\hline & 40 & & 3.138 & 3.160 & 3.169 & & 3.179 & \\
\hline & 60 & & 3.250 & 3.299 & 3.344 & & 3.371 & \\
\hline & 80 & & 3.348 & 3.392 & 3.882 & & 3.375 & \\
\hline & 100 & & 3.653 & 3.650 & 3.650 & & 3.641 & \\
\hline
\end{tabular}

Table 4. Molar volumes $\left(\mathrm{v}_{\mathbf{m}}\right)$, molar polarization $\mathrm{P}$ and Polarizabilities $(\alpha)$ for DB18C6 in mixed $\mathrm{MeOH}-\mathrm{H}_{2} \mathrm{O}$ mixtures at different temperatures

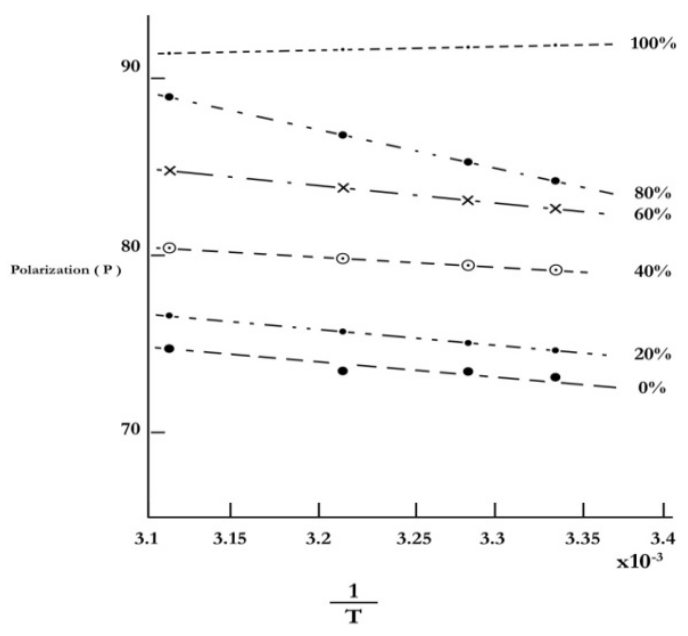

Figure 1. Polarization of saturaled solutions of DB18C6 in mixed $\mathrm{MeOH}-\mathrm{H}_{2} \mathrm{O}$ solvents

and their values are listed in Table (5). Also, from the intercepts the values of $\mathrm{P}_{\mathrm{A}}+\mathrm{P}_{\mathrm{E}}$ are calculated and tabulated in
Table (5). Also, small effect of solvent on the dipole moment of DB18C6 was observed while very influenced effect on $P_{A}$ $+\mathrm{P}_{\mathrm{E}}$ can be understood.

The difference between the molar polarization and the sum of $\mathrm{P}_{\mathrm{A}}+\mathrm{P}_{\mathrm{E}}$ gives the orientation polarization $\mathrm{P}_{\mathrm{o}}$, which will be small for DB18C6 due to its lower dipole moment values in mixed $\mathrm{MeOH}-\mathrm{H}_{2} \mathrm{O}$ solvents.

Table 5. Induced Dipole moment $\mu_{\mathrm{i}}, \mathrm{P}_{\mathbf{A}}+\mathrm{P}_{\mathrm{E}}$ (atomic and electronic polarizations ), Polarization permittivity $\left(\varepsilon_{\infty}\right)$ and solubility parameters $(\delta)$ for DB18C6 in mixed $\mathrm{MeOH}-\mathrm{H}_{2} \mathrm{O}$ Solvents at $25^{\circ} \mathrm{C}$.

\begin{tabular}{ccccc}
\hline $\begin{array}{c}\text { Vol\%of } \\
\mathrm{MeOH}\end{array}$ & $\mu_{\mathbf{i}}\left(\mathrm{x} \mathrm{10}^{-18} \mathrm{esu}\right)$ & $\begin{array}{c}\mathrm{P}_{\mathbf{A}}+\mathrm{P}_{\mathbf{E}} \\
\text { (c.c/mole })\end{array}$ & $\varepsilon_{\infty}$ & ${\mathrm{J} . \mathrm{cm}^{-3} \delta}$ \\
\hline 0 & 1.451 & 74.6 & 1.866 & 7.029 \\
20 & 1.551 & 76.4 & 1.876 & 6.939 \\
40 & 1.645 & 80.4 & 1.888 & 6.820 \\
60 & 1.939 & 85.5 & 1.891 & 6.755 \\
80 & 2.228 & 89.4 & 1.883 & 6.587 \\
100 & 0.949 & 91.7 & 1.858 & 6.233 \\
\hline
\end{tabular}

The decrease in entropy and entropy of transfer values for DB18C6 by more increasing the percentage of $\mathrm{MeOH}$ shown 
in Table (2) is also an evidence that the orientation polarization and the dipole moments decrease in the same order because they are dependent on each other.

The refractive index gives the contribution of the electronic polarization to permittivity $\varepsilon \infty$. The contribution of the atomic polarization can by estimated for organic molecules approximately by $[18,19]$ :

$$
\varepsilon_{\infty}=1.05 \mathrm{n}_{\mathbf{d}}^{2}
$$

The calculated $\varepsilon_{\infty}$ values for DB18C6 are presented also in Table (5) at $25^{\circ} \mathrm{C}$ in mixed $\mathrm{MeOH}-\mathrm{H}_{2} \mathrm{O}$ solvents indicating its small effect. The differential scanning calorimeter (DSC) was used to evaluate the heat of vaporization $\left(\Delta \mathrm{H}_{\mathrm{v}}\right)$ of DB18C6 in solid state and was found to be $75.7 \mathrm{~J} /$ mole with one endothermic peak at $273.2^{\circ} \mathrm{C}$ (Fig. 2), having the order of 0.46 . This verify the heat of solvation values given in Table (2) with also an endothermic behavior of solvation.

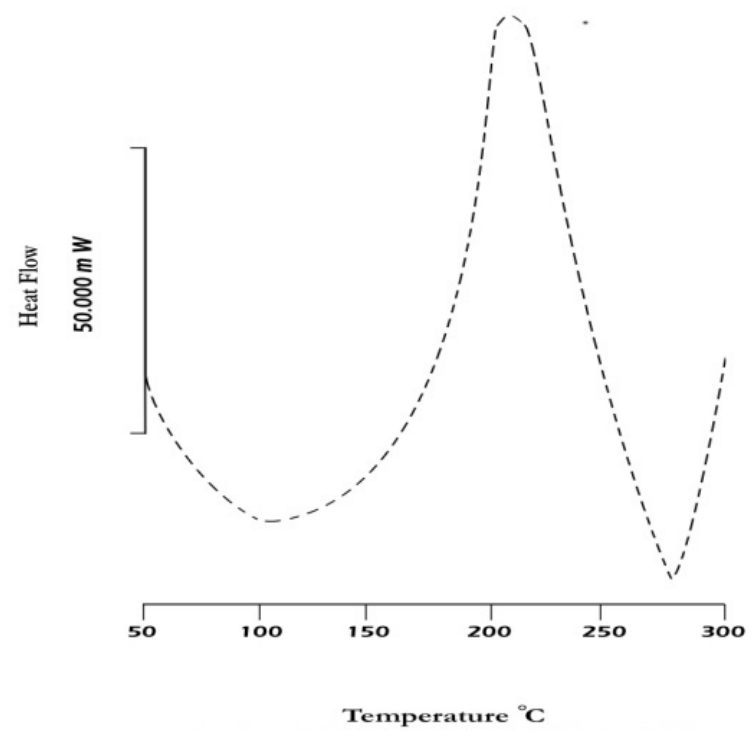

Figure 2. DSC diagram for solid DB18C6

From the heat of evaporization $\left(\Delta \mathrm{H}_{v}\right)$, the solubility parameters (equation 10) for the ether used were calculated by the use of Hildebrand equation[19]:

$$
\delta=\left(\frac{\Delta \mathrm{H}_{\mathrm{v}}-\mathrm{RT}}{\mathrm{v}_{\mathrm{m}}}\right)^{1 / 2}
$$

The calculated $\delta$ values are given also in Table (5) with its small effect on illustrating the solvent mole in solvation processes. Therefore, increasing the mole fraction \% of methanol (organic solvent)[20-22] increases the solubility of DB18C6 in mixed $\mathrm{MeOH}-\mathrm{H}_{2} \mathrm{O}$ solvents due to the increase of molecule- solvent interactions. These molecules - solvent interactions were explained by increase in molar volumes, total polarization, polarizabilites, electronic and atomic polarizations.

\section{Conclusions}

All the solubility and thermodynamic parameters for dibenzo-18-crown- 6 are increased by increasing methanol percentage in the mixed methanol-water solvents. This work give a lot of data about this wide range polycompound for helping in its uses and applications.

\section{REFERENCES}

[1] Dean,A.Richens,David Simpson,Sarah Peterson, Arlo Mc Gim and John D.Lamb, Journal of Chromatography A,1016(2003) 155.

[2] K.Ohta and K.Tanaka,Anal.Chim.Acta,38(1999) 265.

[3] S.Kwon,K.Lee,K.Tanda and K.Ohta J.Chromatogr.,A,850 (1999)79.

[4] T.Okada,J.Chromatogr.,A 758(1997)29.

[5] L.R.Sousa, D. H .Hoffman, L. Kaplan and D .J .Cram, J. Am. Chem. Soc., 96(1974) 7100.

[6] P.Arenaz,L.Bitticks , K.Pannell and S . Garcia, Mutagenesis.4,6,(1989) 438.

[7] Takeda, Yasuyuki ; Kamazawa, Masaomi; Katsuta Shoichi, Anal. Sci, Vol. 6 (2000) 929.

[8] Dankova Marcela Makrlik, Emanueli; Vanura, petr, Models Chem., Vol. 137 (2000) 133.

[9] Bond, Andrew; Dietz, Mark L; Chiarizia Renato, 1nd Eng. Chem. Res., Vol., 39 (2000) 3442 .

[10] Shamsipur, M., Madrakian, T, Polyhedron, Vol. 19 (2000)1681.

[11] Pasti, poola; Matijasir, Ivanko, Tusek- Bozic, lijerka, Inorg. Chim. Acta, Vol. 282 (1998) 76.

[12] Bernal, Pedro; Bunn, Abet; Logam, Jennifer, Me Luann, Jennifer, J. Solution Chemistry, Vol. 29 (2000) 651.

[13] J. I. Kim, A. Cecal, H. J. Born, E. A. Gomaa, Z.Phys. Chemi Neue folge, 110 (1978) 209.

[14] Esam A. Gomaa, Bull - Soc. Chim. Fr, 1 (1988) 56.

[15] Esam A. Gomaa. Thermochim . A cta, 147 (1989) 343.

[16] J. J. Christensen, J.O. Hill and R. M. Izatt, Science, 174(1971) 459.

[17] G.J. Mody and J.D.R. Thomas, "Dipole moments in inorganic Chemistry ", The University of Aberdeen Press, U. K. (1971).

[18] E. A. Moelwyn Hughes "Physical Chemistry" Pergamon Press, London, (1965).

[19] Raymond B. Seymour and Charles Elarraher, "Polymer Chemistry ", Marcel Dekker, New York (1992).

[20] E.A.Gomaa and B.M.Al-Jahdali,American Journal of Fluid Dynamics, 1(1),2011,4-8.

[21] Nagah A.El-Shishtawi,Maany a.Hammada and Esam A.Gomaa, Physical Chemistry, 1(1),(2011) 14.

[22] E.A.Gomaa,Analele Universitate din Bucuresti-Chimie, vol. $19,(2010) 45$. 